\title{
SUSCETIBILIDADE AO MOVIMENTO DE MASSA NO PERÍMETRO URBANO DO MUNICÍPIO DE CHAPECÓ (SC)
}

\author{
SUSCEPTIBILITY TO MASS MOVEMENT IN THE URBAN PERIMETER OF CHAPECÓ \\ MUNICIPALITY (SC)
}

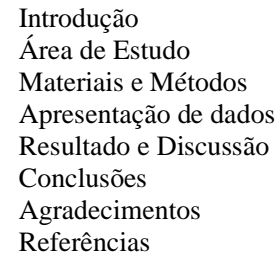

Fábio Alex ZENARO, Júlio Caetano TOMAZONI

UTFPR - Universidade Tecnológica Federal do Paraná. Programa de Pós graduação em Engenharia Civil. Via do Conhecimento, s/n - Km 01 - Fraron, Pato Branco - PR. E-mails: fabiozenaro@yahoo.com.br; caetano@utfpr.edu.br

\begin{abstract}
RESUMO - Este artigo tem a finalidade de apresentar as áreas de suscetibilidade ao movimento de massa no perímetro urbano do município de Chapecó-SC, a partir de estudos do solo realizados com critérios geológicos e geomorfológicos. As análises laboratoriais de solo forneceram as propriedades físicas e geológicas do mesmo. Os resultados identificaram os solos presentes na área de estudo, sendo, 71\% de Latossolos, $23 \%$ de Nitossolos e 6\% de Cambissolos. O teste de infiltração de solo desenvolvido com o método de anéis de infiltrômetro auxilia nos projetos de drenagem, uma vez que o município vem apresentando nos últimos anos um aumento das precipitações anuais de chuva e mostrou que a velocidade básica de infiltração do solo dentre todos os pontos avaliados variou de 64 $\mathrm{mm} / \mathrm{h}$ à $466 \mathrm{~mm} / \mathrm{h}$. A elaboração de mapas temáticos referente à altimetria, direção de encostas e declividade forneceram informações importantes para a elaboração dos mapas de fator de segurança do solo natural e saturado, com e sem vegetação. Esses mapas subsidiam as ações de gestão e planejamento urbano identificando as possíveis áreas de riscos, uma vez que, a maioria delas ainda não foi ocupada e estão dentro do perímetro urbano do município.
\end{abstract}

Palavras-chave: Movimento de massa. Planejamento urbano. Chapecó-SC.

\begin{abstract}
This article has the purpose of presenting the areas of susceptibility to mass movement in the urban perimeter of the municipality of Chapecó-SC, based on soil studies conducted with geological and geomorphological criteria. Soil laboratory analyzes provided the physical and geological properties of the soil. The results identified the soils present in the study area, being, $71 \%$ of Latossolos, $23 \%$ of Nitossolos and 6\% of Cambisols. The soil infiltration test developed with the infiltrator rings method assists in drainage projects, since the municipality has been presenting in recent years an increase in annual precipitation of rainfall and has shown that the basic speed of infiltration of the soil among all the evaluated points ranged from $64 \mathrm{~mm} / \mathrm{h}$ to $466 \mathrm{~mm} / \mathrm{h}$. The elaboration of thematic maps related to altimetry, slope direction and slope provided important information for the elaboration of the natural and saturated soil safety factor maps, with and without vegetation. These maps subsidize management actions and urban planning, identifying the possible areas of risk, since most of them have not yet been occupied and are within the urban perimeter of the municipality.
\end{abstract}

Keywords: Mass movement. Urban planning. Chapecó-SC.

\section{INTRODUÇÃO}

O desenvolvimento urbano do município de Chapecó SC, com industrialização e aumento populacional acelerado vivenciado a partir de 1970, adotou uma nova dinâmica no ambiente. O desmatamento, a construção de vias, edifícios, condomínios residenciais e comerciais, entre outros, alteraram a paisagem natural e não possibilitaram o planejamento do uso e ocupação do solo em todas as áreas do município.

Os espaços urbanos sofrem constantemente ações dos agentes modeladores da paisagem e alterações resultados do desgaste da própria paisagem (Cavalcanti, 2012). Essas intervenções trazem consequências negativas em eventos naturais. Deslizamentos de terras, alagamentos, ou até transbordamento de rios e canais são alguns dos fenômenos naturais no ambiente, que embora não produzam vítimas, afetam a qualidade de vida da população com danos materiais.

Estudos identificando as áreas mais suscetíveis à alteração da paisagem e que necessitam de maior atenção no uso e ocupação do solo contribuem para reduzir os desastres naturais nos espaços urbanos.

Nesse contexto, o estudo tem por finalidade mostrar através de critérios geológicos e geomorfológicos o uso e ocupação do solo no perímetro urbano de Chapecó-SC, identificando as possíveis áreas suscetíveis aos movimentos de massa que podem causar riscos à população. 
As análises de solos, testes de infiltração e elaboração de mapas, são metodologias utilizadas aqui e atendem aos objetivos propostos, podendo fornecer subsídios importantes às ações de gestão e planejamento urbano, na medida em que apre- sentam o comportamento do solo na área de estudos e as possíveis áreas de riscos. Também traz preocupação referente ao futuro da cidade, evitando que ocorram ameaças naturais em ambientes urbanos.

\section{ÁREA DE ESTUDO}

O objeto de estudo desse trabalho concentra-se na área de suscetibilidade ao movimento de massa no município de Chapecó, que está localizada na região oeste do Estado de Santa Catarina, cujo ponto central da cidade localiza-se na latitude Sul de $27^{\circ} 05^{\prime} 47^{\prime \prime}$ e longitude oeste $52^{\circ} 37^{\prime} 06^{\prime \prime}$.

O município abrange uma área total de 626.060 $\mathrm{Km}^{2}$, sendo $86.960 \mathrm{Km}^{2}$ a área de estudo e com 670 metros de altitude média. Está inserida na bacia hidrográfica do Rio Uruguai, cujo curso define a divisa com o Estado do Rio Grande do Sul (Figura 1). Os municípios vizinhos são, basicamente, antigos distritos desmembrados. A área urbana se distribui sobre duas micro bacias: Lajeado São José e Lajeado Passo dos Î́ndios (Baldissera, 2013).

Conta com uma população de aproximadamente 209.553 habitantes que vem crescendo consideravelmente desde os anos de 1970. Esse contingente populacional contribui para a modificação da paisagem no espaço urbano, uma vez que, mais de $90 \%$ da população vive na cidade (IBGE, 2010).

O regime pluviométrico do município se caracteriza por precipitações irregulares com média de $1900 \mathrm{~mm}$ ao ano (Tabela 1). Há grande variação entre volume de chuva e período que elas ocorrem, dificultando o controle de acidentes naturais e sendo cada vez mais necessário o estudo para o uso e ocupação dos solos.

O relevo faz parte do Planalto Meridional do Brasil. A área de estudo compreende especificamente o perímetro urbano do município com áreas já urbanizadas e espaços destinados à ampliação da mancha urbana.

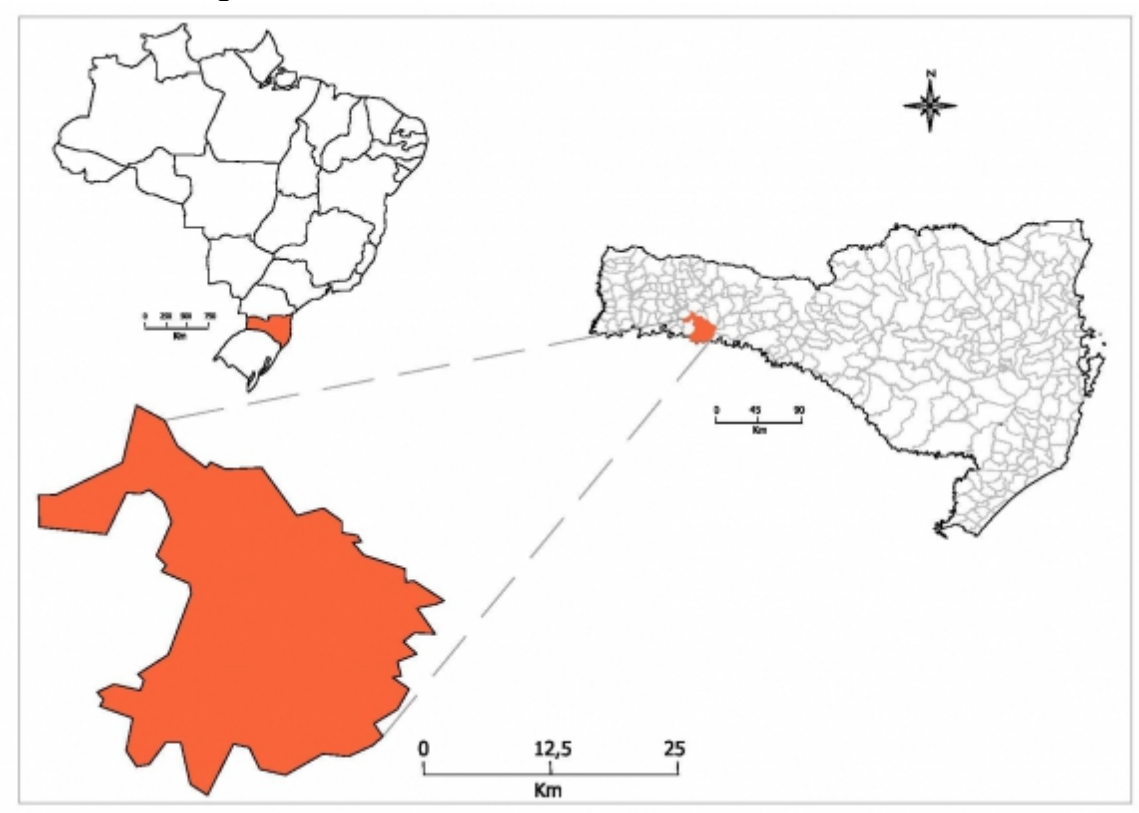

Figura 1 - Localização atual do município de Chapecó-SC. Fonte: Moraes (2014).

\section{MATERIAIS E MÉTODOS}

A identificação das áreas suscetíveis aos movimentos de massa no perímetro urbano de Chapecó-SC, através de critérios geológicos e geomorfológicos, organizou-se em três momentos.

Inicialmente, realizou-se a revisão bibliográfica que trouxe à tona conceitos e métodos possibilitando conhecer melhor os contextos, que norteiam o objeto de estudo e delimitando a área de estudo dentro dos limites administrativos do município de Chapecó-SC, levando em consideração o perímetro urbano da cidade.

$\mathrm{Na}$ sequência, sistematizaram-se dados capazes de compreender o objeto de estudo através de trabalho de campo com coleta de materiais, ensaios de solos e elaboração de mapas temáticos.

Esse trabalho se concentrou em algumas atividades, entre elas:

- Elaboração de tabela de dados pluviométricos do período de 1979 a 2016 a 
partir do Arquivo Digital INMET.

- Produção de banco de dados referente às curvas de nível, hidrografia, divisão da cidade com quadras, lotes e arruamentos, obtidos na Prefeitura Municipal de Chapecó - SC em arquivo digital DWG, com curvas de nível equidistante em 1 metro, os quais foram transformados em arquivos SHAPEFILE possibilitando a sua utilização no programa ARCGIS (Architecture Geographic Information System). Essas informações armazenadas em um banco de dados com arquivos digitais DWG e imagens de satélite CBRES 4 Pan com resolução espacial de 10 metros, as quais foram processadas com programa ARCGIS 10.0 e AutoCAD (Aplicativo de Desenho Assistido por Computador - CAD).

- Elaboração de mapas temáticos com o modelo digital de elevação (MDE), com curvas de nível equidistante 1 metro, processadas no programa ARCGIS, obtendo o relevo da área de estudo e mostrando as diferentes cotas existentes. A partir do modelo digital de elevação (MDE) confeccionou-se o mapa de declividade mostrando em porcentagem as várias declividades que fazem parte da área de estudo, conforme EMBRAPA (2013). Na sequência criou-se mapa de direção de encostas, permitindo conhecer a direção do escoamento superficial, bem como a direção em que os ventos atuam sobre a encosta.

- Confecção do mapa temático dos solos existentes na região de estudo tem como base o mapeamento realizado pela EPAGRI/CIRAM em 2007 em conjunto com a EMBRAPA, que descreve a distribuição dos solos no estado de Santa Catarina. Realizou-se a localização dos solos, objeto de estudo nesse trabalho, através do programa ARCGIS, fazendo um recorte com a ferramenta Clip para obter somente os solos que estão dentro da área de estudo, sendo eles: Cambissolo, Latossolo e Nitossolo (Figura 2)

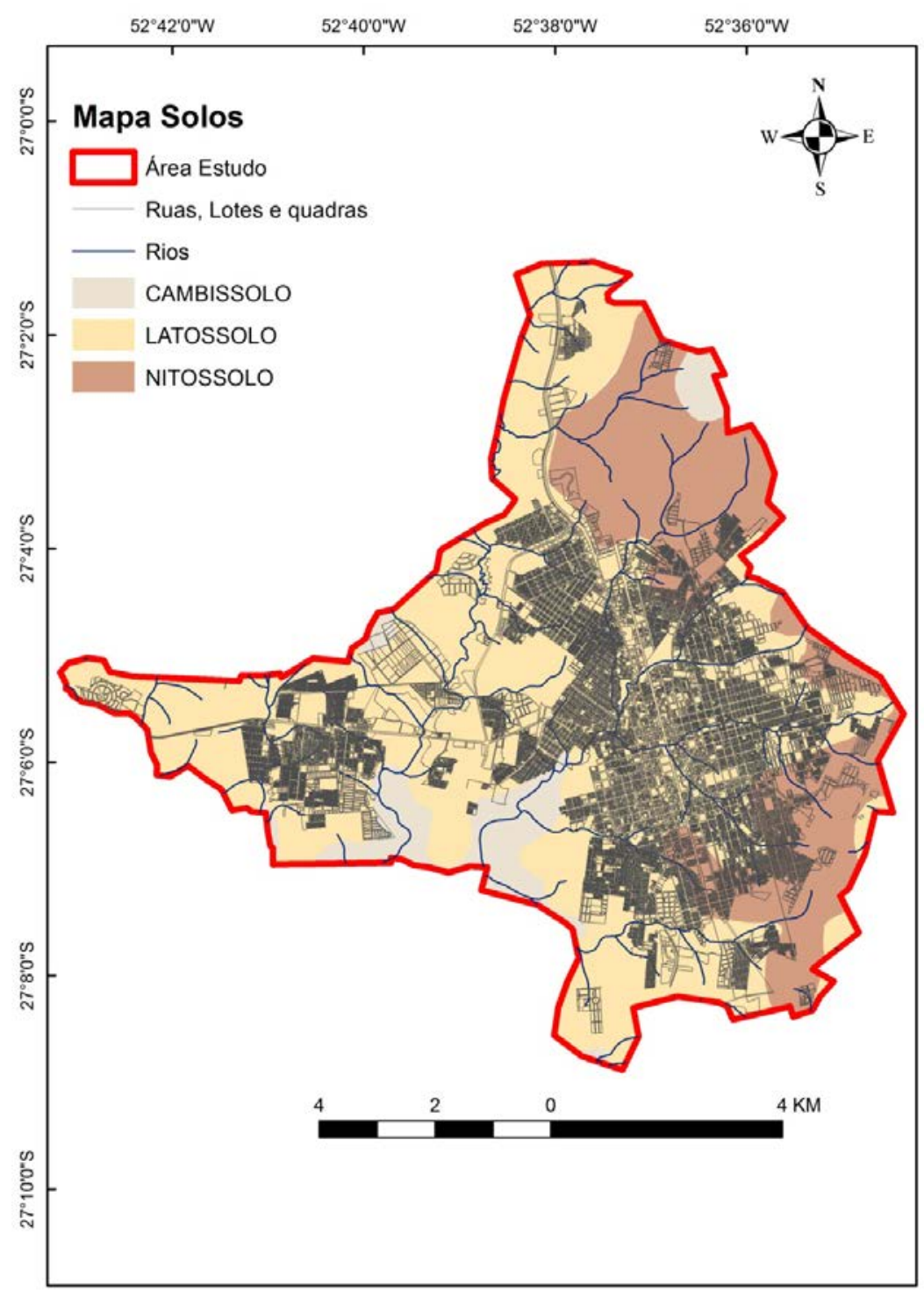

Figura 2 - Mapa Geral das Classes de Solos - Chapecó-SC. 
- Localização de 10 pontos de coleta de solos com a utilização do programa Google maps, de acordo com a declividade e os tipos de solos apresentados pela EPAGRI, sendo: 02 pontos com declividade menos acentuada e solo tipo Latossolo; 04 pontos com maior declividade e solo tipo Cambissolo; e 04 pontos em locais com maior declividade e solo tipo Nitossolo. Todos esses solos situam-se dentro da área de estudo (Figura 3)

- Coleta de solos para ensaios das propriedades físicas e geológicas, que estão dispostas nas áreas de estudo com o uso de um Trado Holandês (Figura 4 a e b)

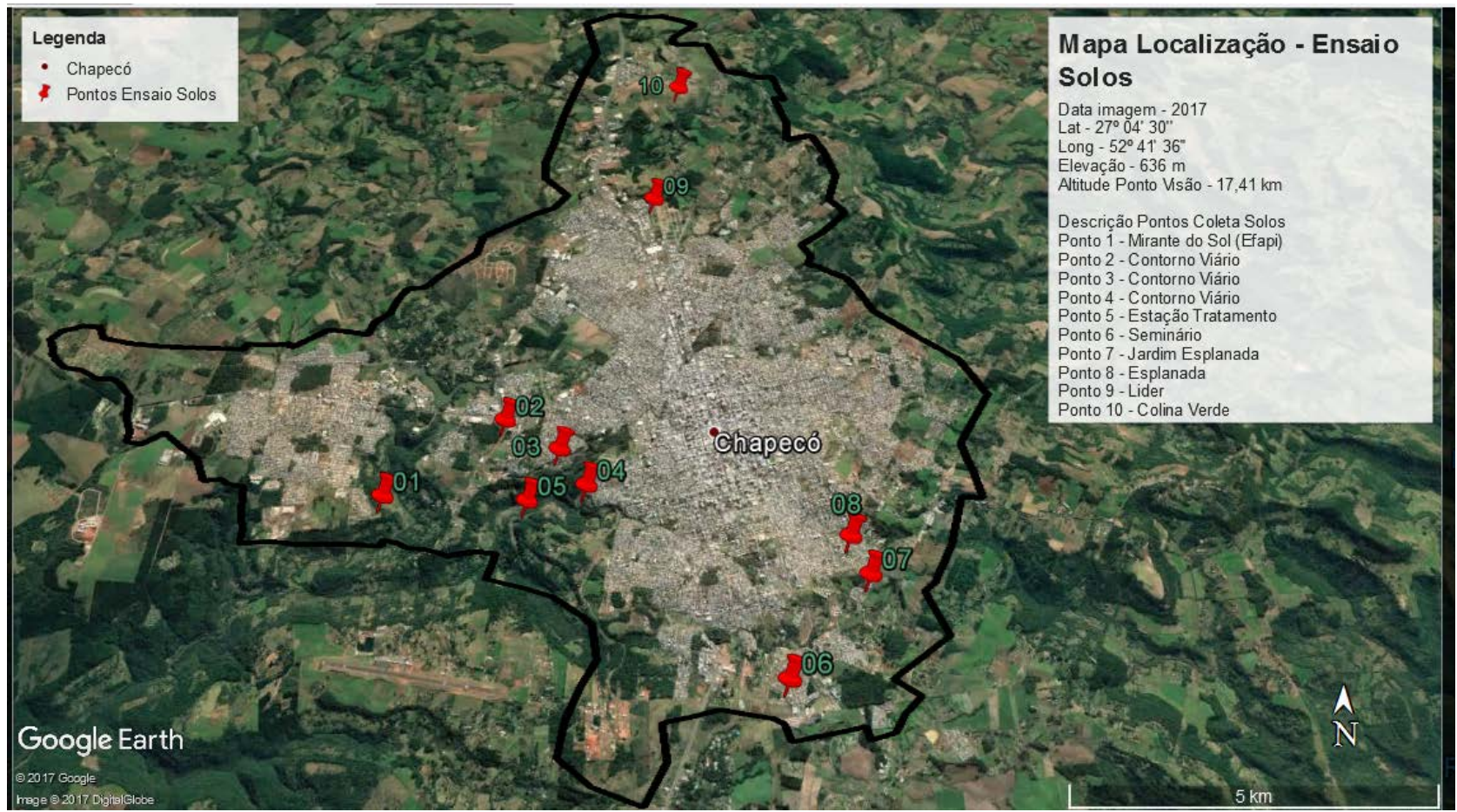

Figura 3 - Localização dos Pontos de Ensaio de Solos.
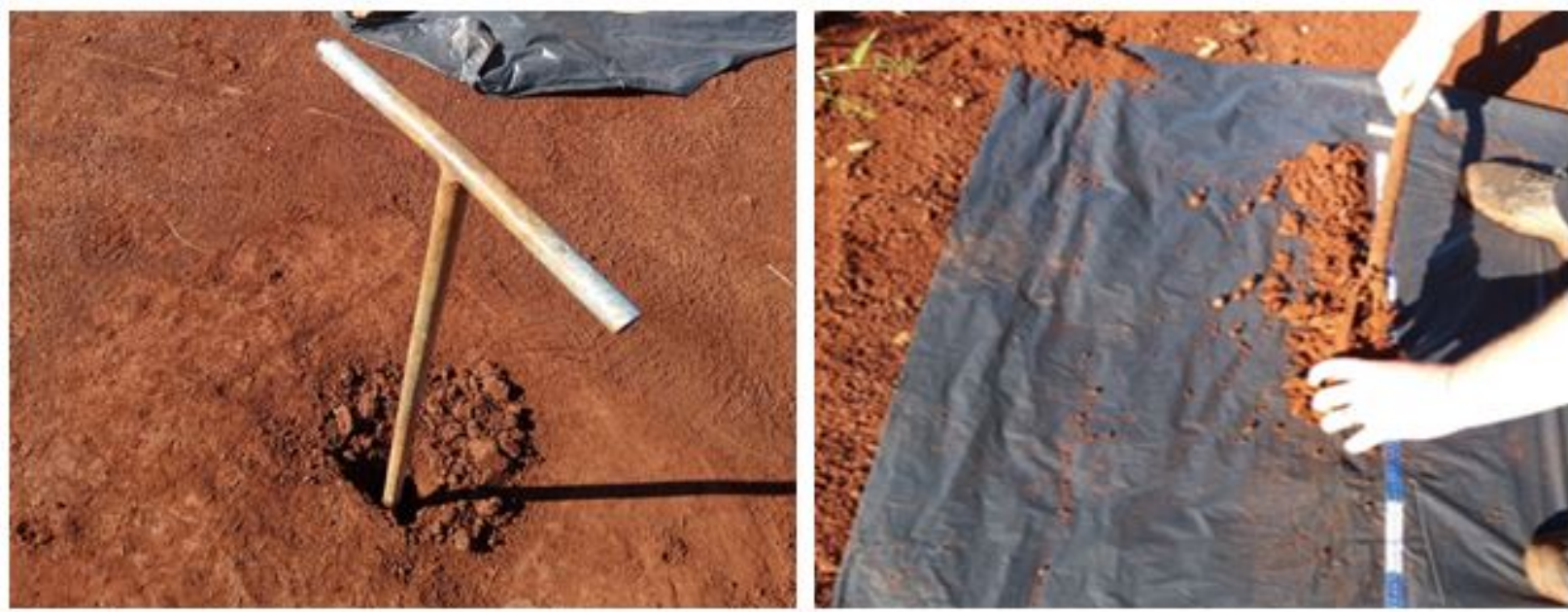

Figura 4 - Coleta de solos para ensaio: a) coleta de solos com Trado Holandês; b) medição de solo coletado.

- Teste de infiltração de solo realizado nos pontos de ensaio, através do método de anéis concêntricos.

- Análises laboratoriais dos solos identificando a classificação textural do material extraído e a sedimentação granulométrica.

- Elaboração de mapa de uso e ocupação do solo na área de estudo utilizando imagem de satélite CBERS 4 com imagem Pan 10 metros, a qual foi classificado com a utilização do programa ARCGIS em diversos tipos de ocupação, como, mancha urbana, floresta, solo exposto e gramíneas.

Após o solo ser retirado e levado ao laboratório, foi seco ao ar e destorroado para então ser analisado com peneira número 200 malha $0,0750 \mathrm{~mm}$, sendo que classifica-se como granulação grosseira $\mathrm{G}$ ou $\mathrm{S}$, quando $50 \%$ do material peneirado fica retido na peneira e considera-se granulometria fina ( $\mathrm{M}, \mathrm{C}$ ou $\mathrm{O}$ ) 
quando o material peneirado passar na peneira com índice superior à 50\%.

De acordo com Pinto (2006), os solos granulares ainda podem ser bem graduados ou mal graduados. Os solos bem graduados são definidos pela existência de grãos com diversos diâmetros, que dá ao solo um melhor comportamento e estabilidade, pois as partículas de menor dimensão ocupam os vazios das partículas maiores, o que resulta em menor compressibilidade e maior resistência, sendo expressa pelo coeficiente de não uniformidade. Quanto maior o coeficiente CNU mais bem graduada são as areias.

$$
\mathrm{CNU}=\frac{D 60}{D 10}
$$

D60 - Diâmetro abaixo do qual se situam 60\% em peso das partículas.

D10 - Diâmetro que na curva granulométrica corresponde à porcentagem que passa, é também conhecido como diâmetro efetivo do solo.

A ABNR 6502 classifica os solos conforme o coeficiente de uniformidade, sendo:

\begin{tabular}{|c|c|}
\hline Uniformes & $\mathrm{CNU}<5$ \\
\hline Mediamente Uniformes & $5<\mathrm{CNU}<15$ \\
\hline Desuniformes & $\mathrm{CNU}>15$ \\
\hline
\end{tabular}

Já para a obtenção da granulação fina do solo realizou-se a análise através dos ensaios de limite de liquidez e limite de plasticidade, conforme figura 5 .

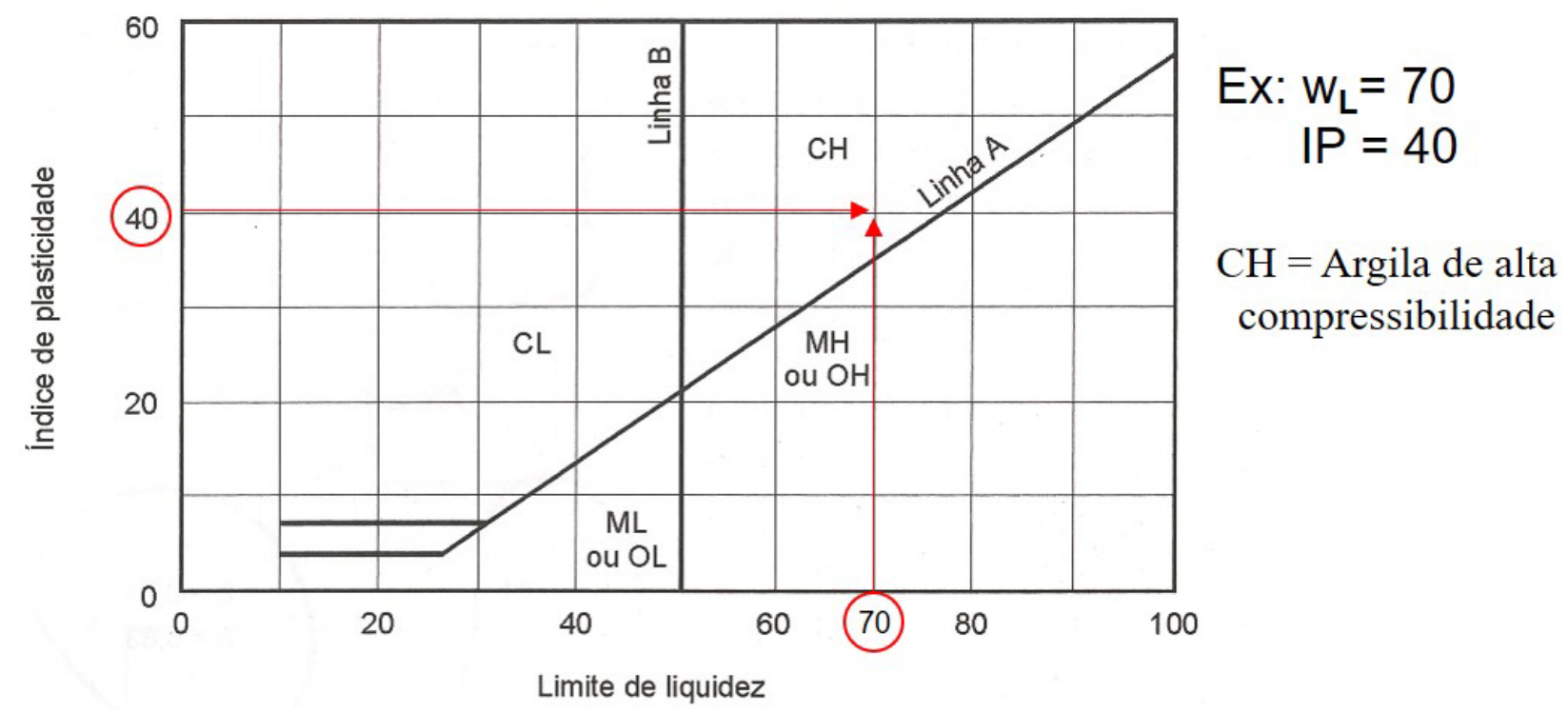

Figura 5 - Carta de Plasticidade do Solo. Fonte: Pinto (2006).

Os resultados são inseridos na carta de plasticidade (Figura 5), em que pode-se classificar os solos em silte (M), argila (C), ou orgânico (O), mas não em função das porcentagens de frações granulométricas silte ou argilas. Isso, pois o que determina o comportamento argiloso não é só o teor de argila, mas também sua atividade e são os índices de consistência que indicam o comportamento argiloso.

Os solos também podem ser classificados em alta compressibilidade $(\mathrm{H})$, ou baixa compres- sibilidade (L), sendo o limite entre (H) ou (L) a linha B com valores acima ou abaixo de 50 .

Por fim, analisou-se os dados sistematizados fornecendo respostas à problematização do objeto de estudo.

Essa atividade possibilita conhecer a forma de ocupação urbana do solo sugerindo ações de gestão, reduzindo os impactos ambientais, os riscos de acidentes e melhorando a precisão das informações para quem toma as decisões no tocante ao planejamento urbano.

\section{APRESENTAÇÃO DE DADOS}

A elaboração de tabela referente às precipitações mensais ocorridas no município de Chapecó- SC entre os anos de 1979 a 2016 (Tabela 1) apresenta que os meses de Fevereiro e Outubro foram em média os mais chuvosos, enquanto Março e Agosto apresentaram as menores precipitações, porém não é possível defini-los como permanente nessa ocorrência.

O ano de 1989 apresentou o menor índice pluviométrico com apenas 1090,20 mm, enquanto que o ano 1998 apresentou o maior índice com 2952,90 mm. 
Esses dados mostram uma média anual de aproximadamente $1900 \mathrm{~mm}$.

Portanto, observa-se irregularidades nas precipitações de chuvas ao longo do ano, não sendo possível definir o período de maior volume. Os primeiros dezoito anos desse período apresentam uma média menor de precipitações em relação aos últimos dezoito anos, demonstrando assim uma tendência ao aumento do volume de chuvas.

Tabela 1 - Dados Mensais de Pluviosidade Acumulada para a Cidade de Chapecó-SC Durante o Período de 1979 a 2016. Fonte: Arquivo Digital INMET.

\begin{tabular}{|c|c|c|c|c|c|c|c|c|c|c|c|c|c|}
\hline Ano & Jan & Fev & Mar & Abr & Mai & $\mathrm{Ju}$ & Jul & Ago & Set & Out & Nov & Dez & Total \\
\hline 1979 & 58,4 & 215 & 56,8 & 120,1 & 195,2 & 30,3 & 73,8 & 81,3 & 62,9 & 286 & 102 & 213 & 1494,80 \\
\hline 1980 & 50,8 & 82.7 & 50,6 & 51,5 & 160,1 & 105,8 & 126,5 & 74,9 & 112,4 & 130,2 & 184,8 & 157,3 & 1204,90 \\
\hline 1981 & 99 & 169,7 & 79,5 & 26,3 & 36,8 & 78,1 & 18,9 & 49 & 100,5 & 115,4 & 117,4 & 305 & 1195,60 \\
\hline 1982 & 82 & 159,2 & 91 & 56,6 & 115,6 & 122,7 & 119 & 94,3 & 97 & 140,3 & 271,5 & 94,8 & 1444,00 \\
\hline 1983 & 87,1 & 334 & 209,8 & 256,7 & 418,8 & 195,6 & 684,8 & 94,4 & 168,6 & 247,5 & 157,3 & 87 & 2941,60 \\
\hline 1984 & 153,3 & 118,7 & 90,3 & 125 & 130,6 & 242,2 & 109,3 & 259,1 & 156,9 & 112,4 & 246,2 & 185,4 & 1929,40 \\
\hline 1985 & 44,3 & 338,3 & 117,2 & 210,5 & 149,3 & 68,8 & 124,8 & 209,3 & 151,1 & 110,7 & 75,1 & 122,5 & 1721,90 \\
\hline 1986 & 100,3 & 97 & 65 & 195,5 & 125,7 & 45,5 & 64,6 & 71,9 & 55,5 & 120,6 & 144,2 & 85,2 & 1171,00 \\
\hline 1987 & 98,3 & 133,5 & 72,1 & 220,15 & 45,8 & 99,5 & 110,7 & 154,2 & 86,4 & 122 & 135,7 & 123,5 & 1401,85 \\
\hline 1988 & 129,8 & 96,1 & 87 & 209,9 & 153,4 & 36,7 & 89 & 95,1 & 43,2 & 73 & 80,2 & 59,3 & 1152,70 \\
\hline 1989 & 219,4 & 116,4 & 75,7 & 122 & 57,1 & 58 & 32,2 & 57,1 & 101,5 & 102,3 & 68,2 & 80,3 & 1090,20 \\
\hline 1990 & 144,3 & 85,5 & 124,8 & 144,8 & 76,5 & 98,4 & 140,7 & 98,5 & 108,5 & 136,8 & 146,8 & 94,1 & 1399,70 \\
\hline 1991 & 95,6 & 115,6 & 160,7 & 140,8 & 107,2 & 99,2 & 87,3 & 168,9 & 154,6 & 91,3 & 83,4 & 118,9 & 1423,50 \\
\hline 1992 & 150,2 & 500,3 & 271,6 & 168,9 & 482,9 & 152,2 & 292 & 163,2 & 174,2 & 206,9 & 254,4 & 117,6 & 2934,40 \\
\hline 1993 & 263,2 & 276,9 & 96,9 & 57,6 & 213 & 134,7 & 179,6 & 52,7 & 286,2 & 233,1 & 163,9 & 167,6 & 2125,40 \\
\hline 1994 & 116,8 & 440,1 & 105,7 & 236,5 & 270,9 & 205,9 & 351,7 & 35,2 & 152,7 & 320,6 & 248,8 & 94,4 & 2579,30 \\
\hline 1995 & 261,4 & 157,8 & 151,3 & 114,7 & 41,4 & 186,1 & 97,5 & 99,9 & 240,4 & 264,1 & 59,1 & 142,5 & 1816,20 \\
\hline 1996 & 313,8 & 227,6 & 191,1 & 66,2 & 62,5 & 191,5 & 130,4 & 281,5 & 221,4 & 330,3 & 146,6 & 244,9 & 2407,80 \\
\hline 1997 & 104,3 & 369,6 & 104,2 & 97,8 & 128,4 & 193,5 & 219,4 & 269,1 & 156,9 & 446 & 261,2 & 234,1 & 2584,50 \\
\hline 1998 & 350,1 & 463,5 & 237,3 & 357 & 153,4 & 86,7 & 149,4 & 302,8 & 330,1 & 294 & 27,4 & 201,2 & 2952,90 \\
\hline 1999 & 247,2 & 201,5 & 58,2 & 229,5 & 89,4 & 136,3 & 243 & 34,6 & 102,5 & 242,2 & 43,1 & 178,7 & 1806,20 \\
\hline 2000 & 228,9 & 131,5 & 89,9 & 121 & 137,7 & 147,3 & 252,4 & 126,3 & 391,5 & 337,6 & 121,2 & 137 & 2222,30 \\
\hline 2001 & 136,2 & 132,4 & 123,8 & 87,3 & 103,2 & 67,7 & 107,2 & 76,6 & 167,5 & 231,1 & 114,5 & 98 & 1445,50 \\
\hline 2002 & 103,2 & 67,7 & 107,2 & 76,6 & 167,5 & 231,1 & 114,5 & 187,1 & 222,5 & 397 & 220,9 & 219,2 & 2114,50 \\
\hline 2003 & 115,6 & 220,6 & 237 & 146,2 & 68,8 & 147,5 & 101,7 & 69,9 & 78,9 & 188,9 & 190,8 & 379,7 & 1945,60 \\
\hline 2004 & 162,5 & 116,1 & 37,5 & 201,1 & 141,4 & 37,2 & 177,4 & 41,7 & 188,7 & 301,4 & 190 & 113,2 & 1708,20 \\
\hline 2005 & 251,8 & 80,2 & 91,6 & 288,3 & 216,1 & 360,9 & 145,3 & 142,1 & 210 & 312,5 & 72 & 48,3 & 2219,10 \\
\hline 2006 & 285,6 & 88,1 & 151,1 & 46,7 & 15,1 & 114,3 & 62,8 & 115,4 & 166,5 & 95,7 & 223,8 & 236,3 & 1601,40 \\
\hline 2007 & 115,5 & 232,1 & 151,1 & 298,4 & 327,9 & 57,7 & 217,5 & 66,6 & 116,4 & 209,2 & 276,4 & 119,6 & 2188,40 \\
\hline 2008 & 95 & 49,2 & 93,4 & 287,1 & 70,7 & 211,4 & 29 & 121,6 & 166,5 & 319 & 126,7 & 43,7 & 1613,30 \\
\hline 2009 & 170,3 & 159,9 & 17,3 & 197 & 80,5 & 144,8 & 240,4 & 440 & 171,9 & 231,7 & 81 & 163,6 & 2098,40 \\
\hline 2010 & 170 & 66,4 & 119,9 & 159,1 & 89,5 & 114 & 98,2 & 126,8 & 146,8 & 155 & 115,5 & 392,4 & 1753,60 \\
\hline 2011 & 168,3 & 247,8 & 227,1 & 120,5 & 59 & 292,4 & 211,4 & 266,9 & 187,2 & 315,1 & 91,1 & 56,7 & 2243,50 \\
\hline 2012 & 86,2 & 98,5 & 85,1 & 197,4 & 47 & 101,6 & 184,8 & 23 & 68,5 & 231,1 & 73,6 & 289,9 & 1486,70 \\
\hline 2013 & 133,6 & 138,3 & 307,4 & 181,7 & 87,9 & 234,8 & 78,7 & 218,3 & 212 & 285,9 & 152,1 & 129,5 & 2160,20 \\
\hline 2014 & 149,6 & 147,2 & 266,3 & 241,8 & 272,9 & 538,8 & 119,5 & 87,3 & 376,7 & 110,4 & 163,3 & 208,7 & 2682,50 \\
\hline 2015 & 307,5 & 182,1 & 142,1 & 115,8 & 208,5 & 124,1 & 498,2 & 54,2 & 274,8 & 209,2 & 335,2 & 376,4 & 2828,10 \\
\hline 2016 & 137,1 & 251,1 & 248 & 75,4 & 173,4 & 36,2 & 64,7 & 182 & 103,1 & 235,8 & 170,9 & 187,1 & 1864,80 \\
\hline Media & 157,54 & 179,22 & 131,38 & 159,20 & 144,24 & 145,51 & 161,80 & 134,02 & 166,13 & 218,22 & 150,96 & 165,96 & 1919,84 \\
\hline
\end{tabular}

Essas irregularidades das precipitações e a tendência ao aumento do volume das chuvas tornam-se preocupante, quando ocorrem chuvas torrenciais muito comuns na região oeste de Santa Catarina, uma vez que, os terrenos com forte declividade podem sofrer movimentos.
Para identificar a velocidade básica de infiltração foram realizados testes de Permeabilidade através do método do Infiltrômetro dos anéis calculando permeabilidade do solo. São dois anéis, um com $15 \mathrm{~cm}$ e outro com $30 \mathrm{~cm}$ de diâmetro e ambos com 30 cm de altura. Estes são cravados no solo há 
uma profundidade entre 5 a $10 \mathrm{~cm}$ (Figura 6a).

Primeiramente se preenche o anel externo com água, o qual é responsável pela neutralzação do efeito de infiltração lateral da água. Em seguida se preenche o anel interno com água, realizando a medição para calcular a velocidade básica de infiltração, conforme figura 6 b. São realizadas várias medições com diferentes tempos de intervalos. Quando após três medições consecutivas não houver alteração no valor medido, considera-se que atingiu a velocidade básica de infiltração (VBI).
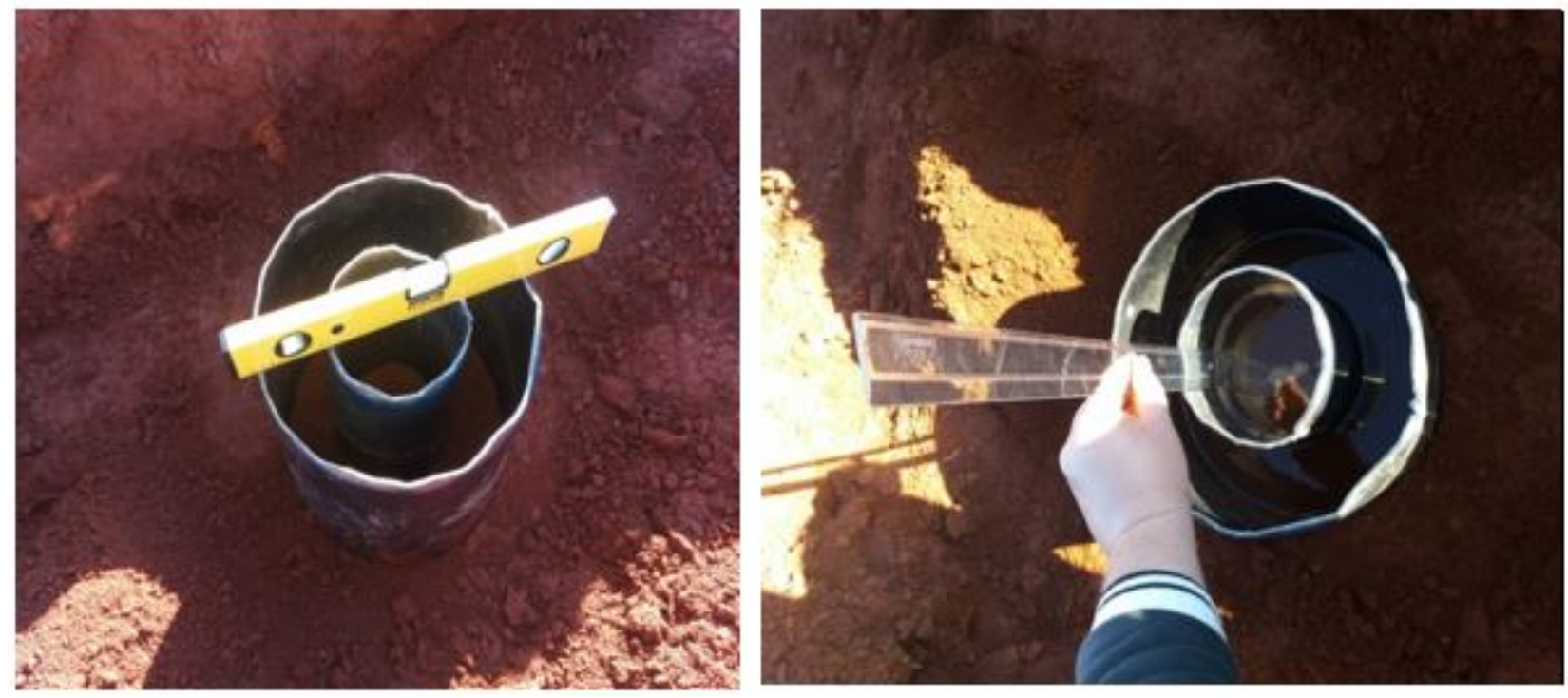

Figura 6 - Ensaio de Permeabilidade: a) Nivelamento e Cravação dos Anéis. b) Medição da Velocidade de Infiltração Básica.

Com este ensaio temos a VBI que pode ser definida em $\mathrm{cm} / \mathrm{h}$ ou em $\mathrm{mm} / \mathrm{h}$ e pode-se comparar esses índices com os apresentados na tabela 2.

Tabela 2 - Velocidade de Infiltração.

\begin{tabular}{c|c}
\hline Tipo de infiltração & VBI (mm/h) \\
\hline Muito Alta & $>300$ \\
\hline Alta & $150-300$ \\
\hline Média & $50-150$ \\
\hline Baixa & $<50$ \\
\hline
\end{tabular}

Fonte: Bernardo et al (2006) apud Fagundes.

Os testes de permeabilidade apresentaram os seguintes dados de velocidade básica de infiltração nos 10 pontos realizados (Tabela 3):

Tabela 3 - Velocidade Básica de Infiltração o Município de Chapecó-SC. Fonte: arquivo do Autor.

\begin{tabular}{l|c}
\hline Pontos & VBI $\mathbf{~ m m} / \mathbf{h}$ \\
\hline 01 -Efapi & 202 \\
\hline 02 - Contorno & 340 \\
\hline 03 - Contorno & 466 \\
\hline 04 - Contorno & 90 \\
\hline 05-Estação Tratamento & 98 \\
\hline 06 - Seminário & 368 \\
\hline 07 - Jardim Esplanada & 80 \\
\hline 08 - Esplanada & 78 \\
\hline 09 - Líder & 64 \\
\hline 10 -Colina Verde & 114 \\
\hline
\end{tabular}

Observa-se conforme tabela 3, que nos pontos avaliados a velocidade básica de infiltração variou de $64 \mathrm{~mm} / \mathrm{h}$ à $466 \mathrm{~mm} / \mathrm{h}$. Nas regiões de solo do tipo Latossolo a velocidade básica de infiltração apresentada foi muito alta, enquanto no solo do tipo Nitossolo foi média. Já os pontos do solo do tipo Cambissolo variaram entre média, alta e muito alta. De forma geral, os solos do perímetro urbano do município de Chapecó apresentaram boa drenagem com valores satisfatórios de infiltração.

O estudo para identificar as áreas de suscetibilidade aos movimentos de massa realizou-se com a elaboração diversos mapas. Inicialmente os mapas de Altimetria, Declividade e Uso e Ocupação do Solo, fundamentais para a elaboração posterior dos mapas do Fator de Segurança dos solos, natural com e sem vegetação e saturado com e sem vegetação. Esse mapeamento apresenta as possíveis áreas de movimento de massa.

Para a confecção do mapa de altimetria, utilizou-se de arquivo digital DWG, com curvas de nível equidistante em 1 metro, os quais foram transformados em arquivos SHAPEFILE possibilitando a sua utilização no programa ARCGIS. Com os arquivos no programa, desenvolveu-se o MDE (Modelo Digital de Elevação), que fornece base para a análise de hipsometria da área de estudo do município de Chapecó-SC.

A menor cota que foi encontrada no mapa é de 497 metros e a maior foi de 796 metros de 
altitude, em relação ao nível do mar. A maior concentração das altitudes está entre as cotas de 612 e 695 metros. A região leste do perímetro urbano do município apresenta as maiores latitudes enquanto na região oeste se concentra as menores cotas.

A elaboração do mapa e da tabela de declividade (Figura 7 e Tabela 4) fornecem informações sobre o tipo de classificação do relevo conforme EMBRAPA (2013) e uma dimensão dos espaços urbanos de maior risco.

Analisando os resultados pode-se observar que a maior parte do relevo na área de estudo é considerado ondulado, variando a declividade de 8 a $20 \%$. Há uma pequena área de declividade acentuada de $45 \%$ a $75 \%$ que necessita de maior atenção nos momentos de intensas precipitações, situada na região sudoeste do perímetro urbano.

Além do processo natural de erosão causado no solo nos momentos de precipitação intensa, com remoção das partículas principalmente em locais com declividade considerável, a intervenção humana acelera esse processo. Santoro (2009) apresenta os condicionantes antrópicos para o aparecimento das erosões: Uso inadequado do solo; Desmatamento; Movimento de Terra; Concentração de escoamento superficial de água.

Tabela 4- Declividade da Área de Estudo.

\begin{tabular}{c|c}
\hline $\begin{array}{c}\text { Declividade em } \\
\text { porcentagem \% }\end{array}$ & $\begin{array}{c}\text { Porcentual da área } \\
\text { total \% }\end{array}$ \\
\hline 0 a 3 \% Plano & $23,50 \%$ \\
\hline 3 a 8 \% Suave Ondulado & $17,80 \%$ \\
\hline 8 a $20 \%$ Ondulado & $38,40 \%$ \\
\hline 20 a 45 \% Forte ondulado & $12,30 \%$ \\
\hline 45 a 75 \% Montanhoso & $6,80 \%$ \\
\hline 75 a $100 \%$ Escarpado & $1,20 \%$ \\
\hline TOTAL & $100 \%$ \\
\hline
\end{tabular}

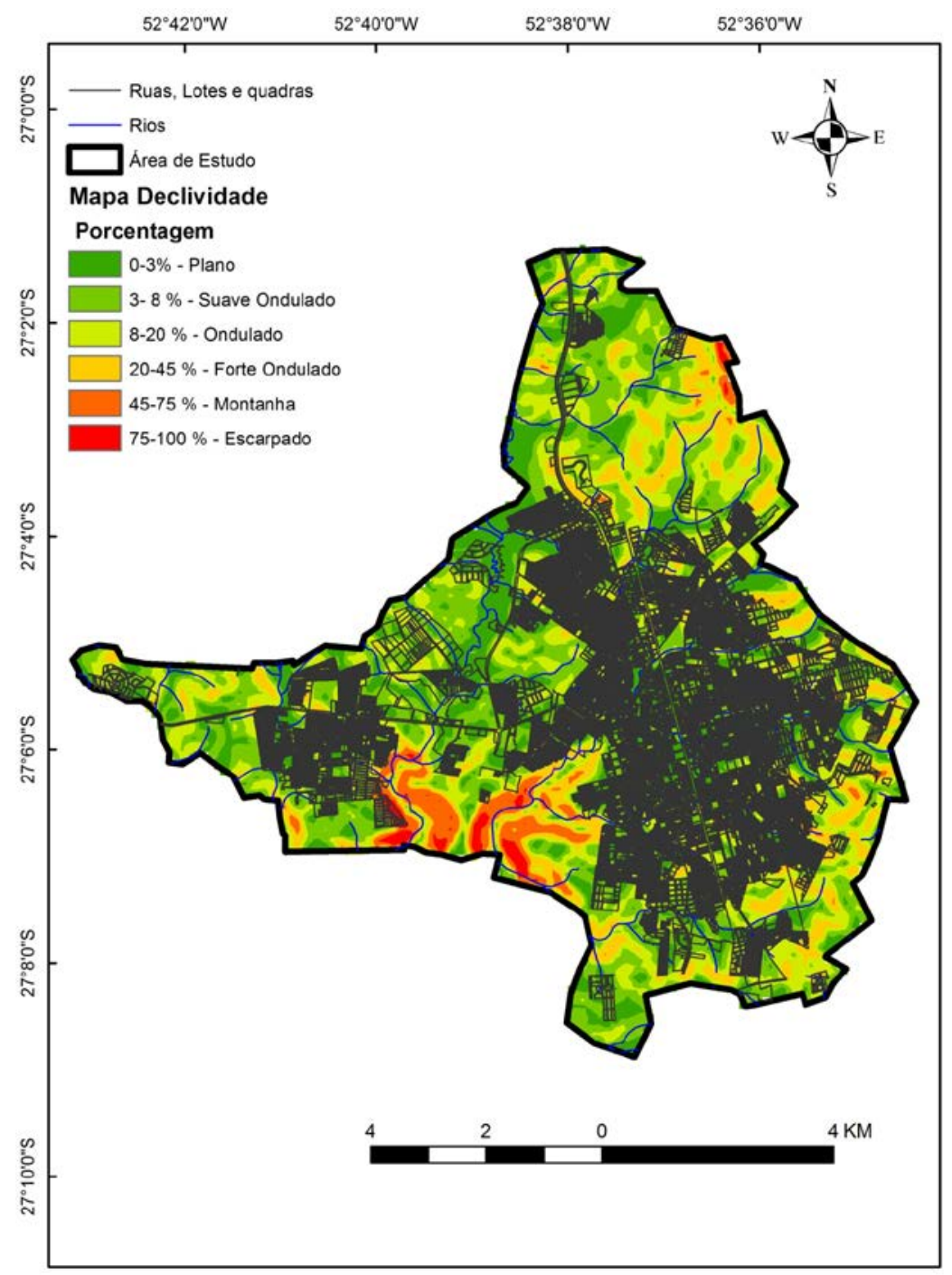

Figura 7 - Mapa Declividade - Chapecó-SC.

Após a elaboração dos mapas de Altimetria e planejamento urbano no que diz respeito à Declividade, elaborou-se o Mapa de Uso e ocupação de novas áreas e evitando riscos à Ocupação do solo, sendo fundamental para o população. Para a confecção desse mapa utilizou- 
se de imagens do satélite CBERS 4, Pan de 10 metros, do qual transferiu-se para o programa ARCGIS e classificou-se em quatro tipos de uso do solo: solo exposto, gramíneas, floresta e mancha urbana. A figura 8 demonstra a ocupação do solo na área de estudo.

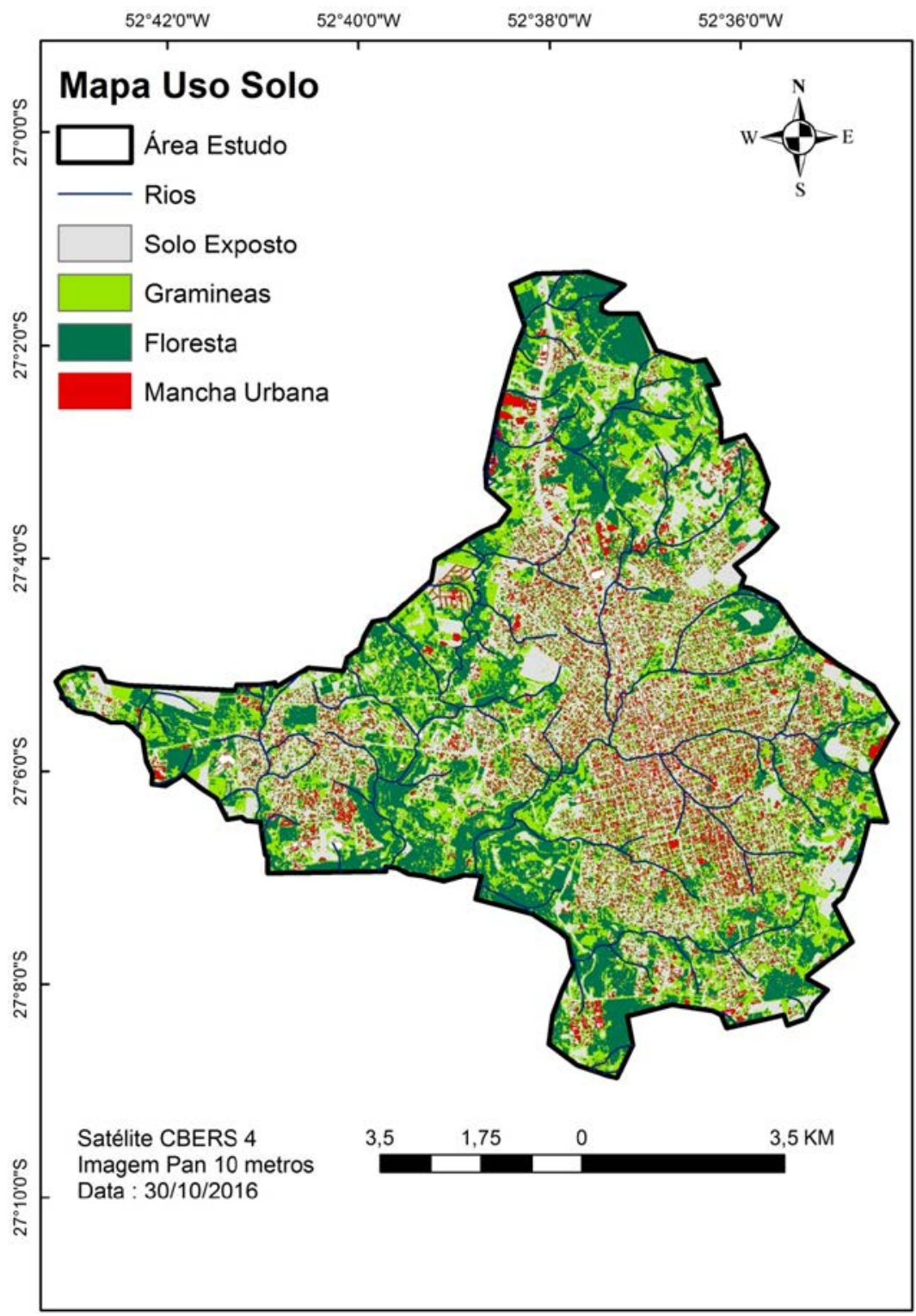

Figura 8 - Mapa de Uso e Ocupação do Solo.

A classificação demonstrada na figura 8 distribui-se pela área de estudo, sendo:

- Solo exposto: localizado na extremidade do perímetro urbano com pequenas lavouras;

- Manchas de gramíneas: espalhadas por todos os bairros da cidade;

- Florestas: presentes na maioria do entorno da mancha urbana e principalmente próxima aos pontos com o relevo mais acidentado, em que o crescimento urbano não chegou;

- Mancha urbana: distribuída em quase toda a área de estudo e dividida basicamente em duas manchas, que ficam bem visíveis. A parte mais antiga da cidade (Centro) e a Grande Efapi. Este último é o bairro que apresenta maior crescimento nos últimos anos, tanto em expansão territorial quanto populacional.

Além da elaboração dos mapas, para compreender esse processo de movimento de massa há de considerar o tipo de solo e suas características, textura, permeabilidade, densidade, que oferecerá maior ou menor resistência à água das chuvas, uma vez que, a água é o principal agente causador desse movimento. Identifica-se essas características através da realização dos ensaios de solos nos dez pontos selecionados na figura 4, sendo específicas e diferenciando entre si na profundidade da coleta, horizonte encontrado e tipo de solo, conforme detalhado na tabela 5 .

Observa-se que os pontos em que os solos apresentaram baixa profundidade foram encon- 
trados horizontes $\mathrm{C}$ ou $\mathrm{R}$, enquanto os solos de maior profundidade chegaram ao horizonte B. O Latossolo possibilitou encontrar maior profundidade, enquanto o Cambissolo e o Nitossolo variaram de acordo com a região. Em regiões próximas o tipo de solo pode ser diferenciado, como o caso dos pontos 02 e 03 que são respectivamente, Latossolo e Cambissolo.
Identificou-se as características geotécnicas do solo através dos ensaios de Limite de Liquidez (LL), Limite de Plasticidade (LP), Teor de Umidade (W) e Peso Específico (y), conforme tabela 6.

Para a classificação unificada do solo da área de estudo utiliza-se o método do professor Casagrande, que consiste em classificar os solos por letras, conforme tabela 7.

Tabela 5 - Localização dos Pontos de Coleta dos Solos, Profundidade da Coleta e Horizonte Encontrado.

\begin{tabular}{c|c|c|c|c}
\hline Ponto & Localização & Profundidade & Horizonte & Classe dos Solos \\
\hline Ponto 01 & Mirante do sol & $0-1,20$ & $\mathrm{~B}$ & Cambissolo \\
\hline Ponto 02 & Contorno Viário & $0-1,20$ & $\mathrm{~B}$ & Latossolo \\
\hline Ponto 03 & Contorno Viário & $0-0,60$ & $\mathrm{C}$ & Cambissolo \\
\hline Ponto 04 & Contorno Viário & $0-0,70$ & $\mathrm{R}$ & Cambissolo \\
\hline Ponto 05 & Estação Tratamento & $0-0,62$ & $\mathrm{R}$ & Cambissolo \\
\hline Ponto 06 & Seminário & $0-1,20$ & $\mathrm{~B}$ & Latossolo \\
\hline Ponto 07 & Jardim Esplanada & $0-0,53$ & $\mathrm{C}$ & Nitossolo \\
\hline Ponto 08 & Esplanada & $0-0,89$ & $\mathrm{C}$ & Nitossolo \\
\hline Ponto 09 & Líder & $0-1,20$ & $\mathrm{~B}$ & Nitossolo \\
\hline Ponto 10 & Colina Verde & $0-1,15$ & $\mathrm{~B}$ & Nitossolo \\
\hline
\end{tabular}

Tabela 6 - Análises Geotécnicas do Solo.

\begin{tabular}{l|c|c|c|c|c|c|c|c|c}
\hline \multicolumn{1}{c|}{ Ponto } & LL & LP & IP & IC & W & ysec & ynat & ysat & ysab \\
\hline 01 -Efapi & 57,63 & 36,63 & 21,63 & 0,79 & 40,62 & 11,45 & 15,66 & 17,32 & 6,54 \\
\hline $\mathbf{0 2}$ - Contorno & 61,30 & 47,37 & 14,30 & 1,19 & 44,22 & 13,58 & 14,81 & 17,65 & 5,92 \\
\hline $\mathbf{0 3}$ - Contorno & 62,90 & 55,84 & 7,06 & 3,78 & 36,15 & 12,78 & 14,45 & 16,27 & 6,20 \\
\hline $\mathbf{0 4}$ - Contorno & 55,35 & 42,21 & 13,14 & 0,29 & 51,54 & 10,86 & 15,40 & 18,94 & 7,63 \\
\hline $\mathbf{0 5}-$ Estação Tratamento & 58,00 & 36,75 & 21,25 & 0,60 & 45,27 & 13,41 & 17,22 & 19,80 & 6,30 \\
\hline $\mathbf{0 6}$ - Seminário & 61,70 & 53,27 & 8,43 & 3,29 & 30,53 & 10,40 & 14,68 & 17,20 & 4,89 \\
\hline $\mathbf{0 7}$ - Jardim Esplanada & 43,50 & 36,26 & 7,24 & 1,43 & 33,13 & 12,65 & 15,47 & 16,90 & 7,65 \\
\hline $\mathbf{0 8}$ - Esplanada & 57,60 & 41,40 & 16,20 & 1,92 & 26,48 & 13,10 & 16,48 & 18,53 & 7,10 \\
\hline $\mathbf{0 9}$ - Líder & 52,30 & 41,28 & 11,02 & 1,72 & 33,26 & 10,35 & 12,86 & 14,28 & 5,88 \\
\hline $\mathbf{1 0}$-Colina Verde & 62,25 & 49,08 & 13,17 & 2,05 & 35,20 & 12,20 & 13,90 & 16,45 & 5,79 \\
\hline
\end{tabular}

Tabela 7 - Classificação Unificada do Solo para a Área de Estudo.

\begin{tabular}{|c|c|c|c|c|c|}
\hline Ponto & Granulometria & $\begin{array}{c}\text { Característica } \\
\text { Secundaria }\end{array}$ & $\begin{array}{c}\text { Granulação } \\
\text { fina }\end{array}$ & Compressibilidade & $\begin{array}{c}\text { Classificação } \\
\text { unificada }\end{array}$ \\
\hline 01 -Efapi & Areia & Bem graduada & Silte & Alta & SW-MH \\
\hline 02 - Contorno & Areia & Bem graduada & Silte & Alta & SW-MH \\
\hline 03 - Contorno & Areia & Bem graduada & Silte & Alta & SW-MH \\
\hline 04 - Contorno & Areia & Bem graduada & Orgânico & Alta & $\mathrm{SW}-\mathrm{OH}$ \\
\hline 05-Estação Tratamento & Areia & Bem graduada & Silte & Alta & SW-MH \\
\hline 06 - Seminário & Areia & Bem graduada & Silte & Alta & SW-MH \\
\hline 07 -Jardim Esplanada & Areia & Bem graduada & Silte & Baixa & SW-MH \\
\hline 08 - Esplanada & Areia & Bem graduada & Silte & Alta & SW-MH \\
\hline 09 - Líder & Areia & Bem graduada & Silte & Baixa / Alta & SW-MLH \\
\hline 10 -Colina Verde & Areia & Bem graduada & Silte & Alta & SW-MH \\
\hline
\end{tabular}

Inicialmente verifica-se a quantidade de finos que passa na peneira $200(0,075 \mathrm{~mm})$. Se a porcentagem for inferior a 50\%, o solo será considerado como granulação grosseira (Pedregulho ou Areia), já se for superior a $50 \%$ a granulação será fina, (Silte, Argila ou Solo Orgânico). Após a definição da granulometria, identifica-se a característica que diz respeito aos solos serem bem ou mal graduados. Por fim, define-se a granulação fina e a compressibilidade do solo com a utilização do Índice de Plasticidade (IP) e do Limite de Liquidez (LL), que são identificados aplicando seus resultados na carta de plasticidade que consta na figura 5.

Após os cálculos dos índices aplicados na confecção dos mapas de suscetibilidade e agrupou-se os dados conforme a declividade e classe de solos, os quais possibilitam gerar valores médios para ângulo de atrito, coesão e peso específico (Tabela 8). 
Tabela 8 - Analise e Sondagem SPT com Agrupamento.

\begin{tabular}{c|c|c|c|c|c|c}
\hline Classe de Solo & Declividade $\%$ & $\boldsymbol{\phi}$ & $\mathbf{c}$ & $\mathbf{y}$ nat & y' sub & y' sat \\
\hline Latossolo & 3 a 8 & 37,74 & 32,12 & 13,75 & 6,46 & 15,47 \\
\hline Latossolo & 8 a 20 & 35,75 & 26,97 & 14,89 & 8,61 & 16,73 \\
\hline Nitossolo & 8 a 20 & 36,31 & 29,62 & 18,90 & 9,16 & 19,30 \\
\hline Nitossolo & 20 a 45 & 34,46 & 28,66 & 19,35 & 10,05 & 20,81 \\
\hline Cambissolo & 20 a 45 & 34,11 & 36,19 & 17,33 & 10,88 & 18,19 \\
\hline
\end{tabular}

\section{RESULTADOS E DISCUSSÃO}

A tabulação de dados referente ao volume das precipitações mensais ocorridas entre os anos de 1979 a 2016, a elaboração de mapas temáticos (declividade e direção de encostas), os ensaios de solo verificando as características físicas e texturais do mesmo, bem como os testes de infiltração possibilitaram mapear as áreas de maior instabilidade frente ao movimento de massa no perímetro urbano do município de Chapecó-SC.

Os dados da precipitação de chuva do município de Chapecó entre os anos de 1979 à 2016 apresentam uma média anual de $1900 \mathrm{~mm}$, com irregularidades de precipitação ao longo do ano, não sendo possível prescrever o período com maior volume de chuva.

Os procedimentos do trabalho permitiram identificar três tipos de solos que foram analisados, mais especificamente em 10 pontos, representando variações quanto às características. A área de estudo apresentou 6\% de Cambissolo, 23\% de Nitossolo e 71\% de Latossolo. Estes solos apresentaram boa infiltração nos testes de permeabilidade.

A pesquisa de campo associado às análises e interpretação dos mapas, produzidos com a técnica do sensoriamento remoto, possibilitam delimitar as áreas mais suscetíveis à movimentos dentro da área de estudo. Os procedimentos permitiram elaborar os mapas de uso e ocupação do solo.

Identificou-se que a maior parte do espaço urbano já ocupado ou para futuras ocupações apresenta declividade favorável de 0 a 20\% com baixo risco. Embora todo o solo requer atenção e estudo no momento da ocupação, uma pequena área desse estudo apresenta um alto risco com declividade que varia de montanhoso à escarpado com inclinação de $45 \%$ a $75 \%$. Essa área de maior declividade se concentra no solo do tipo Cambissolo. No perímetro urbano de Chapecó essa área de maior risco, em sua maioria não foi ocupada, mas pode vir a ser uma vez que, está dentro do perímetro urbano traçado para futuras ocupações.

Para conhecer as áreas suscetíveis ao movimento de massa, calculou-se o fator de segurança na área de estudo, diferenciando o solo natural, com vegetação, saturado com e sem vegetação.

Para o cálculo de fator de segurança foram observadas 04 possibilidades, sendo:

1. Fator segurança para solo natural sem vegetação:

$$
F S=\frac{(c s)+\left[\text { Z.Ynat. } \cos ^{2} \cdot(i)\right] \cdot T g \emptyset}{[(Z \cdot y n a t) \cdot \operatorname{sen}(i)] \cdot \cos (i)}
$$

Para o cálculo do solo natural sem vegetação foi considerado a profundidade $\mathrm{H} 2$ como sendo Zero, e para $\mathrm{H} 1=\mathrm{Z}$, também foi utilizado o peso especifico natural, coesão do solo, inclinação da vertente, tensão das raízes e ângulo de atrito do solo e os dados agrupados na tabela 08 .

2. Fator segurança para solo saturado sem vegetação:

$$
F S=\frac{(c s)+\left[Z \cdot(Y \operatorname{sub}-y a) \cdot \cos ^{2} \cdot(i)\right] \cdot \operatorname{Tg} \emptyset}{[(Z \cdot Y \operatorname{sub}) \cdot \operatorname{sen}(i)] \cdot \cos (i)}
$$

Para o cálculo do solo saturado sem vegetação foi considerado a profundidade $\mathrm{H} 2=\mathrm{Z}$ e para $\mathrm{H} 1$ = Zero, também utilizado o peso especifico submerso, ou seja, para solo totalmente saturado, coesão do solo, inclinação da vertente, tensão das raízes e ângulo atrito solo e os dados agrupados na tabela 8.

3. Fator segurança para solo natural com vegetação:

$$
F S=\frac{(C s+S r)+\left[(Z \cdot \text { Ynat }+P a) \cdot \cos ^{2} \cdot(i)+T \cdot \operatorname{sen}(\theta)\right] \cdot T g \emptyset+T \cdot \cos (\theta)}{[(\text { Z.ynat }+P a) \cdot \operatorname{sen}(i)+F v e] \cdot \cos (i)}
$$

Para o cálculo do solo natural com vegetação foi considerado a profundidade $\mathrm{H} 2$ como sendo Zero, e para $\mathrm{H} 1=\mathrm{Z}$, também utilizado o peso especifico natural, coesão do solo, inclinação da vertente, tensão das raízes e ângulo atrito solo, força do vento atuando na copa das arvores, peso das arvores sobre as vertentes e dados agrupados na tabela 8.

4. Fator de segurança para solo saturado com vegetação:

$$
F S=\frac{(C s+S r)+\left[(Z \cdot Y s u b+P a) \cdot \cos ^{2} \cdot(i)+T \cdot \operatorname{sen}(\theta)\right] \cdot T g \emptyset+T \cdot \cos (\theta)}{[(Z \cdot \operatorname{sub}+Y a)+P a) \cdot \operatorname{sen}(i)+F v e] \cdot \cos (i)}
$$


Para o cálculo do solo saturado com vegetação foi considerado a profundidade $\mathrm{H} 2=$ Z e para H1 = Zero, também foi utilizado o peso especifico submerso, ou seja, para solo totalmente saturado, coesão do solo, inclinação da vertente, tensão das raízes e ângulo atrito solo, força do vento atuando na copa das arvores, peso das arvores sobre as vertentes e dados agrupados na tabela 8.

Posteriormente realizou-se o cálculo de álgebra de mapas (Mapa Declividade, Mapa Uso e Ocupação do Solo e Mapa de Solos) adicionando às formulas na calculadora raster e obtendo como resultado os mapas das figuras 9, 10,11 e 12, nos quais estão presentes os fatores de segurança do solo.

Estes mapas foram classificados com fatores de segurança que variam de 10 até 1 sendo, quanto menor o número, maior a suscetibilidade ao movimento de massa (Tabela 9).
Tabela 9 - Classificação das Encostas Quanto à Estabilidade do Terreno. Fonte: Scalabrin (2016).

\begin{tabular}{c|c}
\hline $\begin{array}{c}\text { Intervalo do Fator de } \\
\text { Segurança }\end{array}$ & Diagnóstico \\
\hline $0<\mathrm{Fs}<1,5$ & Instabilidade \\
\hline $1,5<\mathrm{Fs}<2$ & Estabilidade Crítica \\
\hline $2<\mathrm{Fs}<3$ & Boa Estabilidade \\
\hline $3<\mathrm{Fs}<4$ & Alta Estabilidade \\
\hline $4<\mathrm{Fs}<10$ & Excelente Estabilidade \\
\hline
\end{tabular}

O mapa gerado a partir da primeira possibilidade, Fator de segurança para solo natural sem vegetação (Figura 9) demonstra que o solo natural possui pouca possibilidade de apresentar áreas com suscetibilidade ao movimento de massa, pois os pontos com fator de segurança menor que 1,5 estão em pequenas quantidades localizadas em área com declividade superior a $20 \%$ de inclinação, ou seja, áreas em que as forças solicitantes são maiores que as forças resistentes.

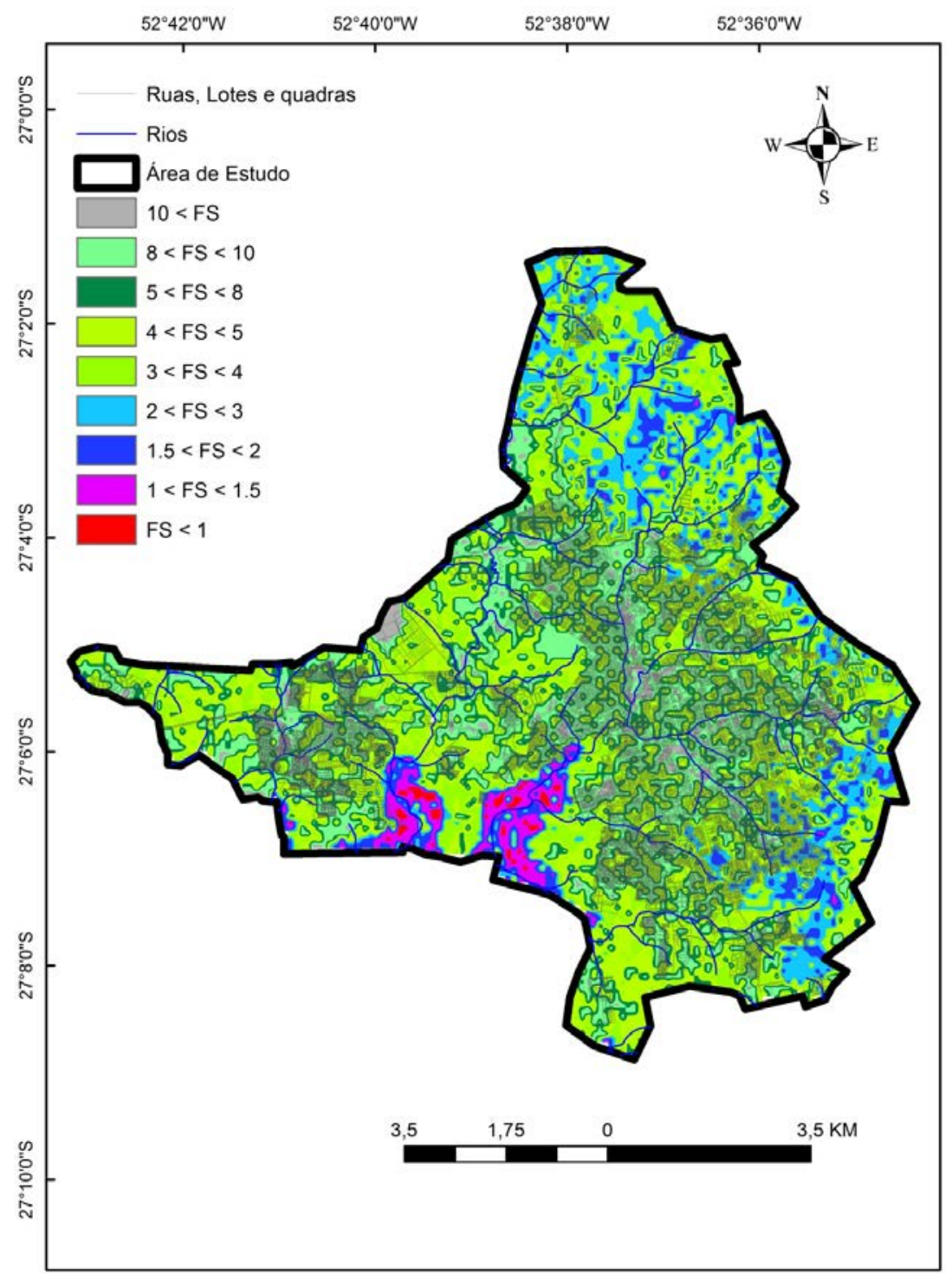

Figura 9 - Mapa Fator Segurança do Solo Natural Sem Vegetação. 
O mapa gerado a partir da segunda possibilidade, Fator segurança para solo saturado sem vegetação (Figura 10), já apresenta maiores pontos suscetíveis ao movimento de massa, ou seja, forças solici- tantes maiores que as forças resistentes, que estão em pontos com declividade maiores que $20 \%$ e estão ligadas aos altos índices de pluviometria, aumentando os índices de fator de segurança menores que 1,5. $52^{\circ} 36^{\prime} 0^{\prime \prime} \mathrm{W}$

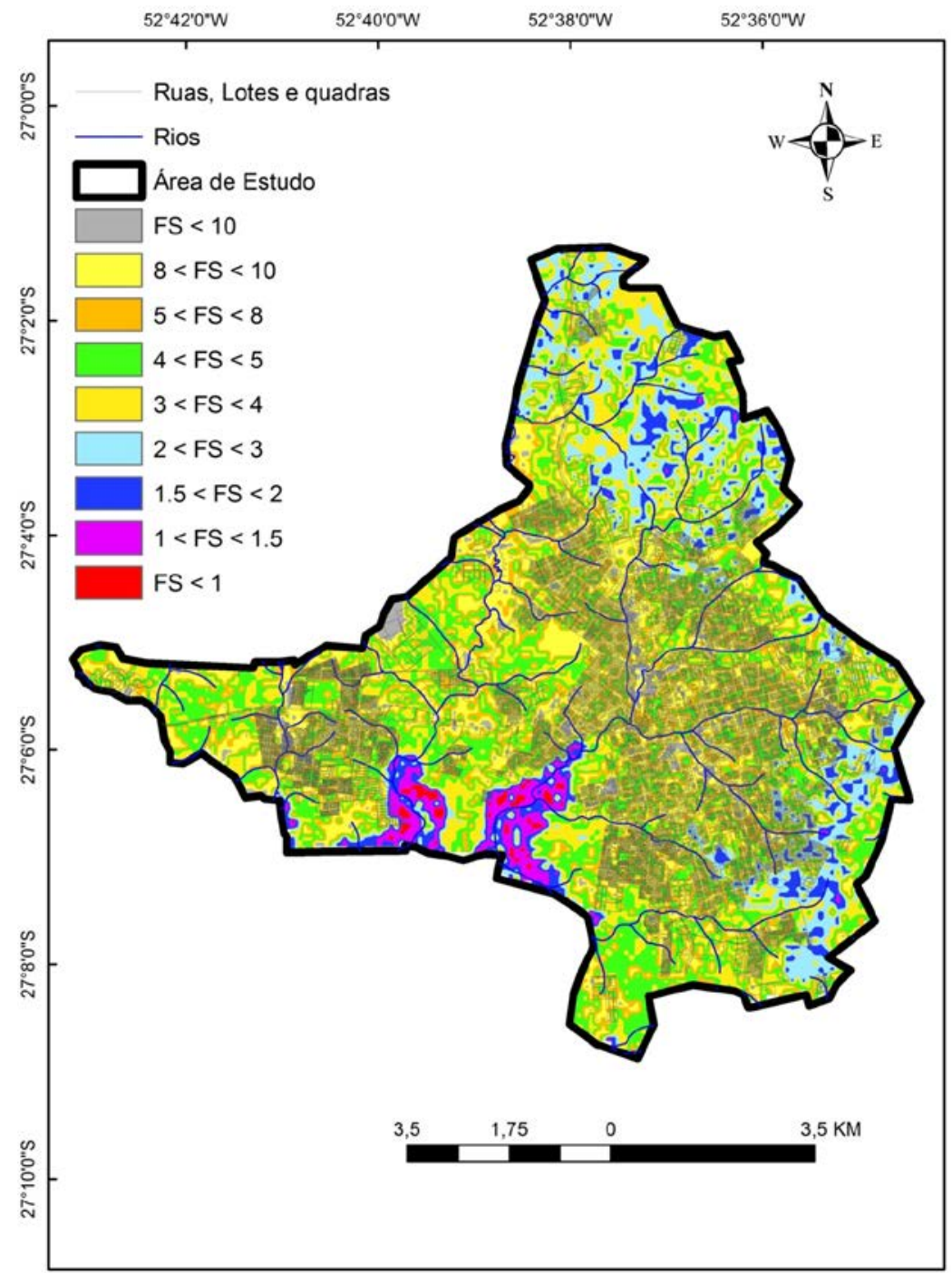

Figura 10 - Mapa Fator Segurança Solo Natural com Vegetação.

O mapa gerado a partir da terceira possibilidade, Fator segurança para solo natural com vegetação (Figura 11), apresenta valores de fator de segurança que demonstram a estabilização do terreno quando se leva em consideração a vegetação como agente protetor, fazendo com que as forças resistentes sejam aumentadas em relação às forças solicitantes, ou seja, reduz a tendência ao movimento de massa.

O mapa gerado a partir da quarta possibilidade, Fator segurança para solo saturado com vegetação (Figura 12), já apresenta menos pontos com suscetibilidade erosiva, ou seja, forças solicitantes são menores que as forças resistentes, devido a ação da cobertura vegetal que proporciona à vertente uma estabilidade, aumentando o fator de segurança do solo para as áreas com declividade elevada acima de $20 \%$.

O mapa do solo natural do perímetro urbano do município de Chapecó-SC (Figura 9), mostra que as maiores suscetibilidades à movimentos encontram-se em faixas estreitas da região sudoeste da área de estudo conhecido como Contorno Viário e Bairro Efapi, além de pequenos pontos de terras em áreas da região leste e norte.

Todos com fator de segurança menor do que 1.5 e áreas não ocupadas ainda. Já as áreas com maior fator de segurança ocupam grande parte da área de estudo se espalhando por todas as regiões do perímetro urbano, principalmente as áreas já ocupadas.

Observa-se nas figuras 10 e 12 que o solo com cobertura vegetal reduz a suscetibilidade aos movi- 


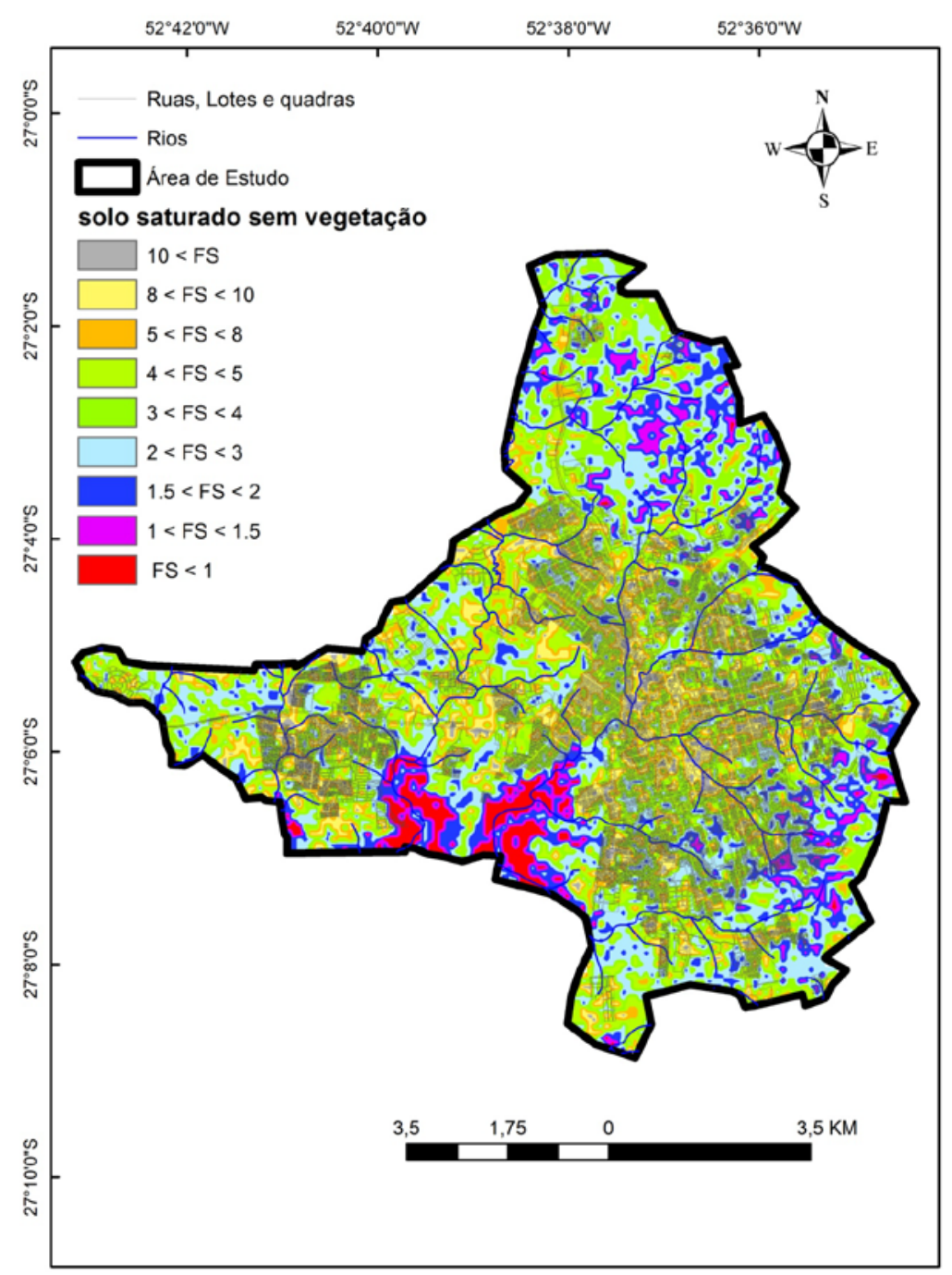

Figura 11 - Mapa Fator Segurança do Solo Saturado sem Vegetação.

mentos de massa e aumenta o fator de segurança, uma vez que, o enraizamento das árvores auxilia no processo de infiltração da água no solo.

O solo saturado sem vegetação apresenta as maiores áreas com fator de segurança menor que
1 , ou seja, as forças solicitantes são maiores que as forças resistentes em relação ao solo com vegetação, demonstrando que a ação antrópica sobre o solo o deixa mais suscetível aos movimentos e traz mais risco à população.

\section{CONSIDERAÇÕES FINAIS}

O município de Chapecó-SC apresenta ao de sua história, um elevado crescimento urbano, tanto populacional quanto territorial. Esse crescimento não possibilitou o planejamento de todos os espaços urbanos, provocando nos momentos de eventos naturais, alterações na paisagem em áreas de grande declividade. A irregularidade das precipitações de chuvas e o aumento do volume apresentado nos últimos anos, incluindo algumas vezes as chuvas torrenciais, tornam-se fundamentais esse estudo identificando as regiões com suscetibilidade ao movimento de massa e evitando riscos nas futuras ocupações do solo.

Os diversos procedimentos metodológicos possibilitaram atingir os objetivos propostos. Os ensaios de solos apresentaram três tipos de solos presentes no perímetro urbano do município de Chapecó-SC e suas respectivas declividades, sendo: $6 \%$ de solo do tipo Cambissolo com declividade de 20 a 75\%; 23\% de Nitossolo com declividade de 20 a $45 \%$; e $71 \%$ de solo do tipo Latossolo com declividade máxima de $20 \%$.

Os testes de permeabilidade apresentaram a boa velocidade básica de infiltração na maior parte do solo, variando de $64 \mathrm{~mm} / \mathrm{h}$ à $466 \mathrm{~mm} / \mathrm{h}$ e auxiliando na drenagem do mesmo, principalmente nos momentos de grande volume de chuvas.

A elaboração de mapas temáticos referente à altimetria, direção de encostas, declividade e de uso e ocupação do solo, forneceram informações importantes para a elaboração dos mapas de fator 


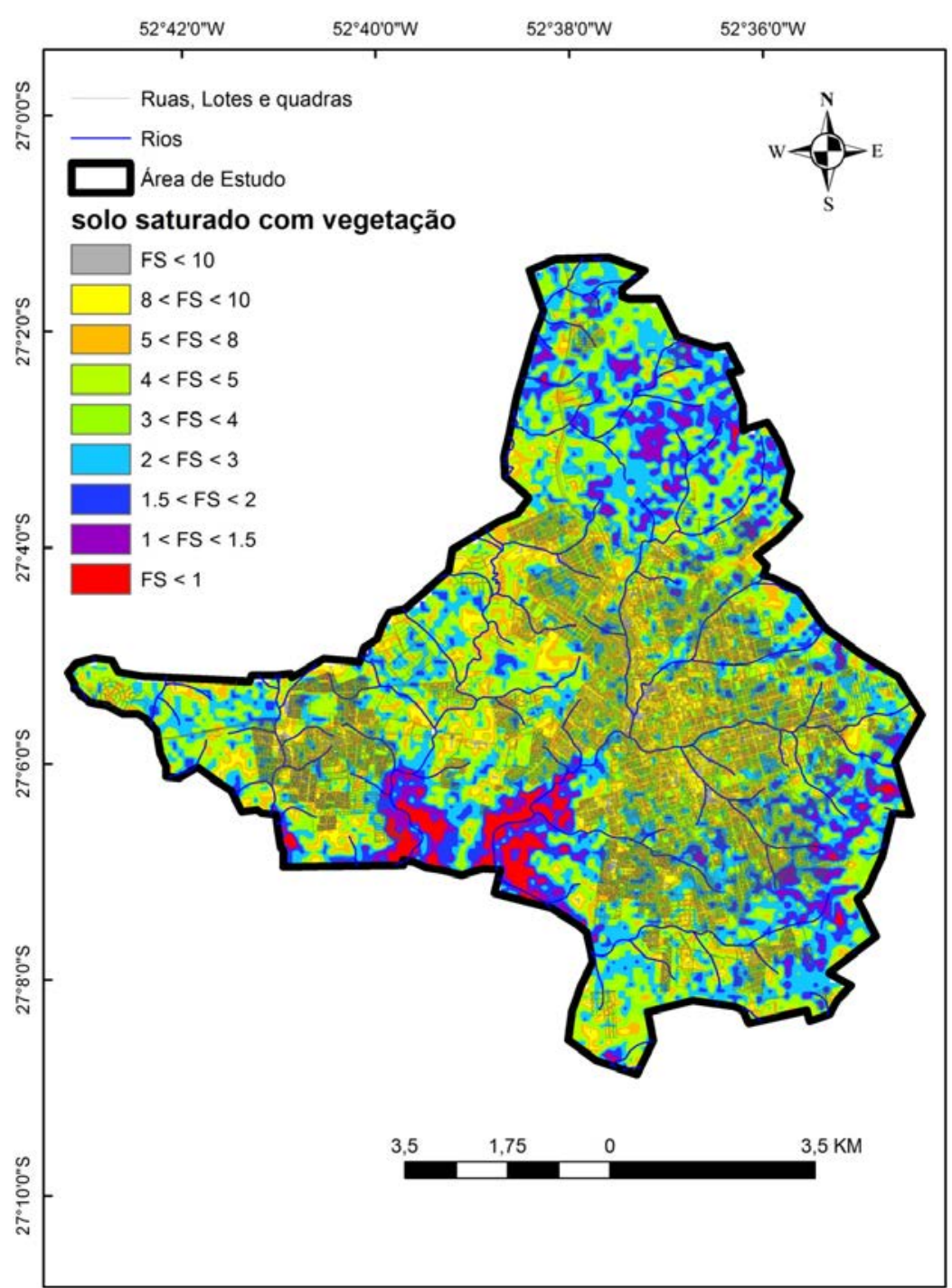

Figura 12 - Mapa Fator Segurança do Solo Saturado com Vegetação.

de segurança do solo natural e saturado, com e sem vegetação. As áreas mais suscetíveis ao movimento de massa foram localizadas em faixas estreitas de solos na região sudoeste do perímetro urbano do município de Chapecó-SC e pequenos pontos da região leste e norte, sendo na maioria em solo do tipo Cambissolo com elevada declividade, que quando saturados e sem vegetação apresentam instabilidade.

Devido à área urbana do município de Chapecó não estar totalmente habitada, esse estudo subsidia as ações de gestão e planejamento urbano apresentando as possíveis áreas de riscos e possibilitando maior qualidade de vida à população.

\section{AGRADECIMENTOS}

Os autores agradecem às instituições que colaboraram com a pesquisa fornecendo informações relevantes e instrumentos para o trabalho, como: Prefeitura Municipal de Chapecó (SC), Epagri (Empresa de Pesquisa Agropecuária e Extensão Rural de Santa Catarina) e UTFPR (Universidade Tecnológica Federal do Paraná) Campus Pato Branco.

\section{REFERÊNCIAS}

ABNT - Associação Brasileira de Normas Técnicas. NBR 6502 Rochas e Solo. Rio de Janeiro, 1995.

BALDISSERA, A.D. A cidade e as águas: Chapecó e a microbacia o Lajeado São José. Florianópolis, 2013. Dissertação (Mestrado). Universidade Federal de Santa Catarina.

CALVANCANTI, R.M.S. Indicadores Geomorfológicos, Riscos e Planejamento Urbano: uma apreciação teórico integradora para a cidade do Recife. Recife. 184 p. 2012. Tese (Doutorado em Geografia), Universidade Federal de Pernambuco.

CAVALCANTI, L.S. O ensino de geografia na escola. Campinas
(SP). Papirus, p. 39-59, p. 175-198, 2012.

EMBRAPA. Sistema Brasileiro de Classificação de Solos. Brasília, DF: Embrapa, 2013.

IBGE - Instituto Brasileiro de Geografia e Estatística. Censo Demográfico. Disp. em: www.ibge.gov.br Acesso em: 06 nov 2015.

INMET. Instituto Nacional de Meteorologia. Banco de Sados Meteorológicos para o Ensino e Pesquisa. Disp. em: www.inmet.gov.br Acesso em 02 Jun 2017.

MORAES, C. Espaços e relações de Poder em Chapecó/SC na década de 1950. Revista Franco-Brasileira de Geografia, n ${ }^{\circ}$ 21, 2014. 
PINTO, C.S. Curso Básico de Mecânica dos Solos. São Paulo: Oficina de Textos, 2006.

PREFEITURA MUNICIPAL DE CHAPECÓ. Arquivo AutoCAD- Chapecó Geral com curvas de nível. Secretaria de Planejamento. Chapecó, 2013.

SANTA CATARINA. Atlas Climatológico do Estado de Santa Catarina. Florianópolis/SC: Epagri, 2007. CD-rom

SANTORO, J. Erosão Continental. In: TOMINAGA, L.K. Desastres Naturais: conhecer para prevenir. $1^{\text {a }}$ ed. São Paulo: Instituto Geológico, 2009.
SCALABRIN, E.C.D (2016). Mapeamento da susceptibilidade de movimentos de massa no perímetro urbano da cidade de Francisco Beltrão - Paraná. Pato Branco. 2016. 176 p. Dissertação (Mestrado em Engenharia Civil) - Universidade Tecnológica Federal do Paraná.

Submetido em 8 de outubro de 2017 Aceito para publicação em 10 de novembro de 2020 